\title{
Estado, poder y dominio. Una lectura a propósito de sus mecanismos
}

\author{
Paola García Reyes, ${ }^{*}$ Jenniffer Vargas, ${ }^{* *}$ Sonia Uribe Kaffure***
}

Perfiles Latinoamericanos, 26(51)

2018 | pp. $191-214$

DOI: $10.18504 / \mathrm{pl} 2651-008-2018$

\begin{abstract}
Resumen
Este artículo ofrece un análisis de las interacciones entre Estado y actores sociales con base en el estudio de tres casos que asocian actores violentos u oportunistas con la promoción del cultivo de palma de aceite en Colombia. Alejándose de las lecturas que describen tales interacciones como de cooptación aquí se propone que su comprensión es mejor si se las visualiza como procesos asociados al ejercicio del dominio indirecto del Estado. Con este fin, además del marco conceptual inherente, se revisan las políticas en cuestión, se acomete una descripción de los casos y se proponen tres mecanismos de dominación indirecta: corsarios, amigos y Gulliveres.
\end{abstract}

\begin{abstract}
This article offers an approach to the interactions between State and social actors, based on the analysis of three cases in which opportunistic or violent actors were associated with policies to promote growing of palm oil in Colombia. We move away from other approaches which describe these interactions as cooptation and suggest they can be better understood as processes associated with the exercise of indirect domination by the State. To this end, we present an overall framework of analysis, review relevant policies, offer a description of the cases, and propose three mechanisms of indirect state domination: privateers, friends and Gullivers.
\end{abstract}

Palabras clave: Estado, dominio indirecto, políticas, mecanismos, palma de aceite, paz. Keywords: State, indirect domination, policies, mechanisms, palm oil, peace.

* Doctora de Investigación en Ciencias Sociales con Mención en Ciencia Política por la Flacso México. Profesora asistente, Departamento de Ciencia Política y Relaciones Internacionales, Universidad del Norte, Colombia. Investigadora del Observatorio de Restitución y Regulación de Derechos de Propiedad Agraria | paolagarcia@uninorte.edu.co

** Estudiante del Doctorado de Investigación en Ciencias Sociales con Mención en Ciencia Política de la Flacso México. Magíster en Estudios Políticos, Universidad Nacional de Colombia. Investigadora del Observatorio de Restitución y Regulación de Derechos de Propiedad Agraria | jennifervr@gmail.com

*** Magíster en Estudios Políticos por la Universidad Nacional de Colombia. Investigadora del Observatorio de Restitución y Regulación de Derechos de Propiedad Agraria | suribek@gmail.com 


\section{Estado, poder y dominio ${ }^{1}$}

E

Estado ha sido visto como un fenómeno concreto analizable como algo separado de la sociedad y su entorno —aquí comprendemos en sentido amplio las aproximaciones de Weber, así como las de los contractualistas agrupados en lo que Bobbio \& Bovero (1984) llamaron el modelo iusnaturalista-, pero también como el resultado construido y contingente de la interacción social —principalmente, pero no exclusivamente, desde las tradiciones marxistas y postmarxistas-. Otras aproximaciones se ubican entre estos dos extremos y proponen miradas que, conservando la "cosificación" analítica del Estado, reconocen su carácter histórico. Este escrito se ubica en ese continuo y parte de dos presupuestos: el Estado puede comprenderse como algo existente, esto es, como un conjunto de instituciones con capacidades diversas que operan sobre el mundo social; y el Estado interactúa con ese mundo social, actuación en la que adquiere materialidad. ${ }^{2}$

La relación del Estado con los actores del conflicto en Colombia ha sido abordada en sus distintas aristas más o menos explícitas por lo que, para efectos de este análisis, distinguimos dos aproximaciones tipo: cooptación y articulación. La primera corresponde a la propuesta de Garay et al. (Garay, De León \& Guerrero, 2008; Garay et al., 2010) y según ella, los Estados colombiano, mexicano y guatemalteco, han sufrido una reconfiguración cooptada en la cual las organizaciones criminales buscan y logran controlar la producción de normas con el fin de aumentar las probabilidades de éxito de su actividad. Esto es así porque la cooptación efectiva de la actividad regulatoria disminuye la coerción que el Estado ejerce sobre ellas (Garay et al., 2010: pp. 6-7). Desde nuestro punto de vista, esta aproximación muestra varios puntos problemáticos: i) que las normas son neutras y no reflejan ningún interés particular lícito o ilícito, ii) que el Estado ejerce o puede ejercer una coerción efectiva sobre la actividad criminal y que por tanto los criminales quieren limitar esa acción, y

1 Este artículo es resultado de las indagaciones realizadas en el marco del Observatorio de Restitución y Regulación de Derechos de Propiedad Agraria, programa de investigación financiado por Colciencias, Colombia. Agradecemos los comentarios de Elisabeth Wood y de Francisco Gutiérrez durante la presentación preliminar de este texto en el Seminario Internacional Tierra y Guerra, realizado en la Universidad del Rosario en Bogotá, Colombia, el 7 y 8 de noviembre de 2014.

2 Estas lecturas pueden calificarse de distinta forma, según la disciplina en la que se inscriban. Típicamente, los análisis institucionalistas y neoinstitucionalistas son propios de la economía y la ciencia política, en particular en sus vertientes más contemporáneas. Mientras que lecturas estructurales, funcionalistas o históricas son más cercanas a la sociología, la antropología y la historia. Desde luego, esta distinción no es ni mucho menos exhaustiva. Dos aproximaciones sintéticas a estas lecturas pueden encontrarse en Rodríguez (2006) y Fernández \& García (2012). 
iii) que la reconfiguración cooptada es un fenómeno estable y no el resultado provisional del cambio de fuerzas de los actores de la política. En nuestro juicio, las normas son el resultado de asimetrías de poder. Piénsese, por ejemplo, que las bajísimas imposiciones que se establecen sobre la propiedad de la tierra en algunos países latinoamericanos reflejan las posiciones dominantes de los actores interesados, entre estos los terratenientes lícitos e ilícitos. El Estado tiene amplios sectores grises en donde su dominio es precario y los actores criminales pueden actuar cómodamente sin necesidad de cooptarlo; y la actividad regulatoria refleja los cambios en las fuerzas en el poder, algunas veces debido a acciones o actividades consideradas como no legales.

La segunda arista propone un relato en el que el movimiento va del Estado hacia los agentes e implica un proceso paulatino de inclusión de actores y regiones (González, 2003; Gutiérrez \& Zuluaga, 2011), el cual se vincula a la centralización/monopolización del poder, con base en la construcción de burocracias nacionales; una noción próxima a las de dominio directo e indirecto de Tilly (1990) y de poder despótico e infraestructural de Mann (1984, 2004). Para Tilly (1990), la consolidación del Estado nacional moderno significó el establecimiento de formas de dominio directo que dejaron atrás las que se fundamentaban en la intermediación entre el poder supremo y los señores locales o dominio indirecto (Tilly, 1990). En un sentido similar, Mann $(1984,2004)$ entiende el poder en dos tipos básicos: el despótico y el infraestructural. El primero consiste en la capacidad de las élites estatales de tomar decisiones sin negociaciones regulares con otros sectores. El segundo, en la capacidad de implementar sus decisiones mediante una infraestructura que penetre a la sociedad civil y que sirva para la extracción y provisión de recursos (Mann, 1984). Estas dos concepciones pueden entenderse como interrelacionadas. Para Mann (1984), el Estado moderno ideal combina un alto poder infraestructural y un bajo poder despótico. Es decir, cuenta con la capacidad de movilizar recursos y reglas de forma efectiva en todo su territorio, mediante mecanismos, digamos, democráticos. ${ }^{3}$ Aunque el poder infraestructural solo es universal en teoría, su ausencia evidente puede devenir en dominio indirecto, en tanto que al no contar con la capacidad de implementar las decisiones a lo largo del territorio, delega ciertas funciones en una gama diversa de actores locales.

Esta aproximación da pauta para entender el clientelismo como una forma indirecta de presencia estatal (González, 2003: p. 151), y muestra la necesidad de incluir en los análisis la intermediación de actores ilegales en la

3 Aunque la democracia no involucra poder despótico, los Estados nación lo ejercen en alguna medida (Mann, 1984).

P. García Reyes, J. Vargas, S. Uribe Kaffure | Estado, poder y dominio. Una lectura a propósito de sus mecanismos Perfiles Latinoamericanos, 26(51) | FLACSO México | pp. 191-214 | DoI: 10.18504/pl2651-008-2018 
comprensión de procesos particulares (Gutiérrez \& Zuluaga, 2011). En la base de estas distinciones se encuentra la pregunta sobre cómo observar al Estado en sus tres dimensiones canónicas: el grado en que ejerce el monopolio de la fuerza, su capacidad burocrática y su alcance territorial. Como lo señala Gutiérrez (2010: p. 101), durante las últimas décadas en Colombia se avanzó en el primero a costa de ceder control territorial a agentes ilegales que lograron capturar parte del sistema político. Lo que esto indica no es un hecho total o definitivo, sino procesos que deben entenderse en su complejidad y cambio. ${ }^{4}$

En este artículo exponemos una lectura de la construcción del Estado colombiano a partir de la implementación de una política específica: la promoción de la palma de aceite ${ }^{5}$ como cultivo de paz. Para ello hacemos un recuento de las políticas de fomento de este cultivo y su articulación con las políticas de paz. Después presentamos las narrativas de tres casos en los que dichas políticas se aplicaron en territorios afectados por el conflicto, con la incorporación de actores violentos y oportunistas, la elección fue deliberada y obedeció a nuestro interés por comprender cuáles son los mecanismos de construcción de dominio indirecto del Estado que operan allí, más que contrastar cuándo ocurre el dominio indirecto y cuándo no, lo cual es objeto de otro artículo en preparación y requiere del análisis de hechos contrafácticos. Esta sección se alimenta de indagaciones de campo realizadas entre 2010 y 2014 en las que se recogió información de diversas fuentes primarias y secundarias como entrevistas, expedientes judiciales, versiones libres de paramilitares y fuentes periodísticas. Así, se arribó a tres mecanismos (Elster, 1998) que han permitido comprender la forma en que Estado y actores interactuaron para producir desenlaces indeseados e ilegítimos. La sección final del artículo se dedica a reseñar un conjunto de proposiciones y moralejas institucionales.

4 Un análisis relevante sobre el caso africano es el de Boone (2013). En este la autora propone la existencia de distintas topografías asociadas a elecciones institucionales que derivan del carácter jerárquico y/o autónomo de las élites locales.

5 Planta oleaginosa de cuyo fruto prensado se extrae aceite. Propia de climas cálidos, crece por debajo de los $500 \mathrm{msnm}$, en la franja ecuatorial. Integrada a la cadena de los aceites y las grasas, su explotación comprende la agroindustria de la palma, las industrias de transformación del aceite y una comercialización. De esa planta se obtienen aceite crudo, almendra, aceite crudo de palmiste y torta de palmiste; en tanto que del procesamiento, concentrados para la alimentación animal, jabones, grasas alimenticias, aceites comestibles, combustibles, lubricantes y pinturas, entre otros. Los principales productores de palma en el mundo son Malasia e Indonesia, con más de dos millones de hectáreas sembradas. Colombia tiene 150000 ha, de las cuales se cosecha un $71.1 \%$ de aceite crudo. Por sus requerimientos de extensión (5000 ha por plantación) y de intensidad de mano de obra ( 0.85 trabajadores por ha), su cultivo se ha vinculado a conflictos sobre la propiedad y a demandas por la apropiación indebida de tierras campesinas e indígenas (Mingorance, 2006). 


\section{Palmas para la paz}

“QQué puede hacer la palma por la paz nacional?”, se lee en la publicidad de las revistas de la Federación de Palmicultores de Colombia (Fedepalma) ${ }^{6}$ de la década de 1980. La misma nota responde: al generar empleo rural estable y bien remunerado, satisface las esperanzas de miles de colombianos; al desarrollar zonas selváticas y marginadas crea asentamientos humanos organizados e incorpora servicios de salud, vivienda, educación, agua potable, electrificación y recreación. Esta concepción de la palma como motor de desarrollo en zonas marginadas sirvió de base para su articulación con las políticas orientadas a culminar el conflicto armado colombiano. ${ }^{7}$ Las palabras del presidente de la junta directiva de la Fedepalma al finalizar su congreso en 1984 señalaron el camino para ese cultivo que recorrerían gobiernos posteriores.

Que este congreso se recuerde como el punto de partida de un extraordinario crecimiento en el cultivo de palma africana, el cual tiene que ser un propósito nacional. Su crecimiento incidirá, sin lugar a dudas, en la labor de paz en la que está comprometido el presidente Belisario Betancur, porque cultivar la tierra es sembrar la paz. Recordemos que Malasia, antes de la palma africana, era un país infestado de guerrillas y afectado por la subversión, hoy es un país de paz. Imitemos a los malasios (Castro, 1984).

Esta convergencia entre palma y paz se dio en el marco de las políticas liberalizadoras propias de la época, en las que el Estado se convirtió en un facilitador de la actuación de los actores privados, más que en un promotor directo del desarrollo. ${ }^{8}$ A partir de 1990, las iniciativas propiamente económicas se combinaron con los esfuerzos de democratización del sistema político derivados de la coyuntura del cambio constitucional de 1991, de modo que el vínculo

6 Fedepalma es una asociación privada que agremia a los cultivadores de palma en el país. Se fundó en 1962 para promover el desarrollo autónomo del sector.

7 Las primeras políticas para apoyar este cultivo datan de finales de la década de 1950. En esa época, el gobierno echó mano de una fórmula mixta de explotación siguiendo tres estrategias: desarrollo de plantaciones de quinientas hectáreas, mediante un esquema de asociación con particulares; apoyo a la iniciativa de pequeńos y medianos cultivadores, y desarrollo de planes de colonización dirigida alrededor del cultivo. El éxito de las políticas fue heterogéneo, con mayores impactos en las dos primeras estrategias (Guerra, 1987; Ospina, 1998).

8 Fernández \& García (2012: p. 42) describen estos procesos como de reescalonamiento y propios de las políticas neoliberalizadoras "a partir de la cesión de funciones a las instancias subnacionales y a organismos supranacionales" que facilitaron el desmantelamiento del Estado central y aumentaron la fragmentación intraestatal. Nuestro punto de vista es que, como en otros países latinoamericanos, las políticas agrarias y de desarrollo fueron parte de esas transformaciones.

P. García Reyes, J. Vargas, S. Uribe Kaffure | Estado, poder y dominio. Una lectura a propósito de sus mecanismos Perfiles Latinoamericanos, 26(51) | FLACso México | pp. 191-214| DOI: 10.18504/pl2651-008-2018 
terminó por estrecharse bajo un modelo que es posible llamar de dominio indirecto (Tilly, 1990) para el desarrollo y la paz. Para ampliar el área sembrada, los palmicultores plantearon impulsar esquemas asociativos entre grandes y pequeños cultivadores9 (Palmas, 1995).

Esta propuesta se articuló bien con los esfuerzos de desarrollo en zonas de conflicto armado emprendidos por el gobierno en turno. En 1998, el empresario palmero, Carlos Murgas Guerrero, fue nombrado ministro de Agricultura y Desarrollo Rural. Desde su gabinete afirmaba que plantar grandes extensiones de palma era una oportunidad promisoria "para desarrollar el agro colombiano, erradicar la pobreza, controlar la violencia y resolver el gravísimo problema social que desde tiempos inmemoriales sacude y atormenta al campo colombiano" (Murgas, 1999: p. 90). Así, se fijó la meta de sembrar quinientas mil nuevas hectáreas en diez años en el marco de las "Alianzas productivas y sociales para sembrar la paz", ${ }^{10}$ un mecanismo social y productivo, cuyo propósito era reactivar el sector agropecuario (Murgas, 1999: p. 90). Los recursos serían aportados por el Estado mediante herramientas como el incentivo de capitalización rural (ICR) ${ }^{11}$ o préstamos de la banca multilateral (Murgas, 1999).

Durante los años siguientes, el gobierno adoptó más medidas dirigidas al sector agropecuario en general y al de la palma en particular. En 2000, promovió el Programa Nacional de Reactivación Agropecuaria, ${ }^{12}$ que contemplaba la compra a agricultores pequeños y medianos a favor de los intermediarios financieros. En esa misma fecha, se amplió el porcentaje del ICR del 20 al 30\% de los costos totales de instalación y sostenimiento del cultivo para medianos y grandes palmicultores. Si los cultivos se enmarcaban en las Alianzas se elevaba al $40 \%$.

9 Estas alianzas no son exclusivamente colombianas, sino episodio de procesos neoliberalizadores más amplios que determinan la actual explotación de la palma. Así, en los noventa, la expansión del cultivo en Honduras, segundo productor regional después de Colombia, promovió un modelo de coinversión liderado por el Estado. De este modo, las empresas campesinas producen el bien primario, mientras que las plantaciones privadas procesan y comercializan el aceite. Este modelo ha recibido críticas porque distribuye el riesgo para los campesinos y el valor agregado del procesamiento para los empresarios (Edelman \& León, 2013: p. 1713).

10 Esta figura fue parte del programa Alianza Interamericana de Empresarios con Interés Social, que promovía el cambio en la estructura empresarial en la región otorgando recursos a proyectos con un componente importante de interés social; con ello se privilegiaban las inversiones que vinculaban a los empresarios, la sociedad civil y el Estado (Austin, 2005; Mosquera, 2000).

11 El incentivo de capitalización rural fue creado por la Ley 101 de 1993 y se reglamentó con el Decreto 626 de 1994. Fue concebido como un derecho de toda persona natural o jurídica que emprendiera nuevos proyectos de inversión financiados total o parcialmente por el Fondo de Financiamiento para el Sector Agropecuario (Finagro). Se traduce como dinero efectivo que se abona al saldo del crédito otorgado.

12 Decreto 967 de 2000, con el que se adopta dicho programa y se fijan los términos y condiciones para su operación. 
Se creó además el Fondo de Inversión Agropecuaria (FIA) con el que se aportaba capital de riesgo para cultivos permanentes. Como novedad, se determinó que el esquema incluiría un seguro de "desorden civil"13 (Villalba, 2000).

Dentro de la estrategia de desarrollo alternativo del Plan Colombia, ${ }^{14}$ el gobierno propuso el fomento de la siembra de palma de aceite en 34000 hectáreas hasta 2005 en zonas afectadas por el conflicto (Echeverry, 2000). Así, la palma africana, cuyo cultivo tenía grandes posibilidades de expansión y contaba con un gremio consolidado, en los cálculos fue "uno de los más importantes y promisorios renglones en sus potenciales de expansión y de mejoramiento económico de vida y de paz en regiones y comunidades rurales, hoy en condiciones precarias." (Villalba, 2000: p. 191).

Las políticas fueron profundizadas durante el gobierno del periodo 20022006, a través del programa Manejo Social del Campo, el cual respaldó intervenciones con esquemas asociativos y productivos para el desarrollo rural. Para los cultivos de plantación, este programa priorizó su ampliación con lo que se buscaba garantizar la rentabilidad y la aplicación del ICR para beneficio de los pequeños productores asociados con modelos propios o en alianzas entre grandes y medianos empresarios. Para ellos el incentivo sería de 40\%, y para los demás, del $20 \% .^{15}$

El énfasis en la ampliación del área sembrada de palma provino de cuatro necesidades: generar empleo rural; presentar alternativas a las economías ilícitas; absorber a la población desmovilizada en el marco del proceso de Justicia y Paz con las Autodefensas Unidas de Colombia (AUC), ${ }^{16}$ y aliviar la presión energética del país (Palmas, 2004). En 2007, el gobierno adoptó la "Estrategia para el desarrollo competitivo del sector palmero colombiano" (Conpes 3477), planeada para mejorar la competitividad del sector y promover la comercialización del aceite de palma y sus derivados. Este documento señalaba

13 Las quince solicitudes para nuevas siembras de palma aprobadas durante el primer semestre comprendían más de la tercera parte de los recursos comprometidos para el ICR, con una meta de crecimiento en el área sembrada de 57500 ha en los siguientes tres años (Villalba, 2000).

14 Es un programa diseñado por el gobierno de Andrés Pastrana (1998-2002) para un periodo de seis años que se ha venido extendiendo hasta la fecha y que se orientaba a terminar con el conflicto armado, luchar contra el tráfico de drogas y promover el desarrollo social. Este programa contó desde sus inicios con el financiamiento del gobierno estadounidense (Vaillette, 2005).

15 Ley 812 de 2003 con la que se aprueba el Plan Nacional de Desarrollo 2003-2006, hacia un Estado comunitario.

16 En 2002, el gobierno inició un acercamiento con las AUc, grupo armado antisubversivo que se había creado formalmente en 1997, con el fin de lograr su desmovilización. Los diálogos culminaron con el "Acuerdo de Santafé de Ralito para contribuir a la paz de Colombia”. Entre 2003 y 2006, se desmovilizaron 31651 integrantes de las AUc, de los que 4500 fueron postulados para acceder a los beneficios de una pena alternativa de máximo ocho años a cambio de confesión plena y reparación a las víctimas (Alto Comisionado de las Naciones Unidas para los Refugiados, 2006). 
que Colombia tenía 3.5 millones de ha potencialmente aptas para la palma, por lo cual propuso aumentar el área sembrada de 303000 ha, en 2006, a un mínimo de 422000 ha, para 2010, consolidando, además, los esquemas asociativos de pequeños productores. Estableció, por otra parte, que la palma era una alternativa lícita cuya promoción sería articulada a las agencias dedicadas a la atención de zonas de conflicto (Agencia Presidencial para la Acción Social y la Cooperación Internacional) y a la sustitución de cultivos ilícitos (Programa Presidencial contra Cultivos Ilícitos).

Este modelo de desarrollo por delegación previsto por el Estado, en el que la palma se concibió como un cultivo pacificador, tuvo consecuencias específicas. A continuación presentamos tres hechos ilustrativos y mostramos las implicaciones.

\section{Los casos}

Coproagrosur: la cooperativa fachada en San Pablo y Simití (sur de Bolívar)

Los municipios de San Pablo y Simití se ubican en el sur de Bolívar en la zona del Magdalena Medio en el centro-norte colombiano. ${ }^{17}$ Dedicados fundamentalmente a la explotación minera, la agricultura y la ganadería intensiva, en los años ochenta experimentaron la presencia de las FARC y del Ejército de Liberación Nacional (ELN).

A mediados de los noventa, las Autodefensas Campesinas de Córdoba y Urabá (ACCU) y, posteriormente, el Bloque Central Bolívar de las Autodefensas Unidas de Colombia (AUC), llegaron a controlar esta zona altamente militariza$\mathrm{da}^{18}$ y para ello tejieron estrechos vínculos con la fuerza pública. ${ }^{19}$ Sus acciones incluyeron masacres, torturas, homicidios de personas protegidas y desplazamientos masivos, entre otros. ${ }^{20}$ Según fuentes oficiales, entre 1996 y 2005, más de dos mil personas fueron asesinadas en la región y según las cifras del Registro

17 Estos dos municipios presentan un alto nivel en el índice de necesidades básicas insatisfechas: 62.00 para Simití y 65.93 para San Pablo. Pero se agudiza en las zonas rurales: 73.50 y 79.67, respectivamente (DANE, 2012).

18 Allí se asentaron cinco batallones del ejército colombiano y dos brigadas móviles contraguerrilla.

19 Sentencia del Tribunal Superior del Distrito Judicial de Bogotá contra Rodrigo Pérez Alzate. Sala de Justicia y Paz. 30 de agosto de 2013. Véase también: versiones de Rodrigo Pérez Alzate y de Iván Roberto Duque en audiencia con la Magistrada Uldi Teresa Jiménez López del 6 de abril de 2016.

20 Fiscalía General sobre patrón de macro criminalidad de Homicidio del Bloque Central Bolívar. Informe de Policía Judicial de fecha de 29 de julio de 2013. Fiscal 22 Delegada ante Tribunal. Unidad Nacional de Fiscalías para La Justicia y la Paz. Folios 1-39. Fiscalía General de la Nación. sobre patrón de macro criminalidad de desplazamiento forzado del Bloque Central Bolívar. Informe de Policía Judicial 80606 (s. f.). Fiscal 22 Delegada ante Tribunal. Unidad Nacional de Fiscalías para La Justicia y la Paz. Folios 1-29. 
Único de Víctimas (RUV), entre 1985 y marzo de 2014 salieron expulsadas de allí $197585 .^{21}$

La violencia paramilitar se relacionó con el abandono de las tierras y desplazamiento forzado en tiempos en los que el gobierno nacional impulsaba la política de fomento al cultivo de palma de aceite. Hacia finales de la década de 1990, el gobierno departamental, de la mano de inversores privados, crearon una empresa de economía mixta denominada Palmas del Sur, para el cultivo de cinco mil ha de palma en los municipios de Simití y San Pablo. Unos años después, los comandantes del Bloque Central Bolívar decidieron crear un ambicioso negocio de palma de aceite, concentrando para sí tierra de antiguos ganaderos y agricultores de los dos municipios. De esta forma se apropiaron de doce predios que sumaban 2125 hectáreas para conformar lo que denominaron "la reserva estratégica del bloque" en referencia a las arcas de dinero, propiedades o recursos que reuniría para su desmovilización. ${ }^{22}$

Según versiones de los mismos paramilitares, los predios fueron comprados con dinero proveniente del narcotráfico. ${ }^{23}$ No obstante, los antiguos propietarios sostienen que los predios fueron vendidos forzadamente a precios inferiores a los del mercado y que algunos fueron abandonados sin recibir el dinero de la venta (Verdad Abierta, 2009). Con el fin de acceder a los incentivos gubernamentales, el grupo creó la Cooperativa Promotora Agraria para la Sustitución de Cultivos Ilícitos en el Sur de Bolívar (Coproagrosur), para lo cual incorporó a varios desmovilizados y personas de la región cuyo papel sería fungir como asociados, pese a que el patrimonio de esta cooperativa correspondió únicamente a los recursos del bloque. ${ }^{24}$

Para la financiación del proyecto, la Coproagrosur accedió a un crédito de $\$ 1600000000$ M.N. (\$550000 dólares actuales) del Banco Agrario y recibió el apoyo financiero del Plan Colombia, con recursos provenientes de la cooperación internacional, ${ }^{25}$ "buscamos una manera legal para poder captar algunos

21 De los dos municipios, el más expulsor fue San Pablo con un total de 36133 personas desplazadas. Simití es el cuarto municipio expulsor del Magdalena Medio con 14990 personas. Cifras consultadas en el Ruv en agosto de 2014 con corte a marzo de ese ańo.

22 Audiencia Pública en Justicia y Paz de Rodrigo Pérez Alzate del 15 de febrero de 2012.

23 Audiencia Pública en Justicia y Paz de Rodrigo Pérez Alzate del 6 de abril de 2016.

24 "Fue tan deficiente esa vigilancia [del Estado] que los papeles nos resultaron perfectos. Inclusive, ahora la Superintendencia [de Economía Solidaria] no sabe quiénes son los socios de esa cooperativa, dijo Duque" (Verdad Abierta, 2014, 6 de junio).

25 Desde 2002, el Plan Colombia autorizó cerca de 75 millones de dólares anuales para sustituir y prevenir la siembra de cultivos ilícitos mediante programas de "desarrollo alternativo", como la producción de palma de aceite. Estos fondos se destinan a proyectos en los que se articulen empresarios agroindustriales y campesinos. USAID aportó a Coproagrosur \$228570 631 M.N. (\$814000 dólares) (Verdad Abierta, 2014, 6 de junio). 
auxilios, inclusive la USAID que es una institución de los Estados Unidos que hace parte del Plan Colombia, aportó 200 millones de pesos para este proyecto". ${ }^{26}$

Aunque en el corto plazo los paramilitares lograron sus objetivos y se beneficiaron de las grandes ganancias del cultivo de palma, ${ }^{27} \mathrm{el}$ proyecto tuvo al menos tres efectos negativos. En primer lugar, el grupo armado concentró la tierra. Segundo, surgieron nuevos conflictos pues los antiguos dueños reclamaban haber sido despojados de sus propiedades por parte de los paramilitares. Por último, las tierras terminaron dedicadas a un monocultivo de plantación, desplazando a otras actividades agrícolas y ganaderas.

\section{Tibú (Norte de Santander)}

El municipio de Tibú se encuentra en la región del Catatumbo, la cual forma parte del departamento Norte de Santander, en el norte de Colombia que hace frontera con Venezuela. Desde finales de la década de 1970, hubo allí presencia de guerrillas, con predominio de las FARC a partir de 1980. En 1999, las AUC incursionaron violentamente en el territorio, con el apoyo de unidades y mandos del Ejército y la Policía Nacional (Semana, 2009, 5 de julio; Verdad Abierta, 2012, 14 de marzo). Su dominio se prolongó hasta 2004, cuando el grupo con acciones específicas en la zona (Bloque Catatumbo) se desmovilizó.

La ofensiva paramilitar estuvo dirigida a expandir el dominio territorial y apoderarse de las economías ilegales, especialmente la cocalera (Salinas \& Zarama, 2012). La estrategia fue altamente punitiva e instauró un verdadero "régimen del terror" contra la población civil, con el fin tanto de combatir las guerrillas como de "pacificar" el territorio mediante la expulsión o exterminio de todo aquel que pudiera constituirse en base social del enemigo (Gutiérrez, 2014; Uribe, 2014).

El RUV reporta un total de 26188 homicidios y 2121 desapariciones forzadas entre 1985 y 2014, en la región. De ellos, 15833 y 1421, respectivamente, ocurrieron durante el periodo de hegemonía paramilitar. Así mismo, fueron desplazadas 52481 personas. ${ }^{28}$ De ellas, 37490 (71.4\%) fueron expulsadas en el periodo 1999-2004. Este éxodo forzado trajo consigo el abandono masivo de las tierras rurales y con esto un cambio de hecho en la tenencia de la tierra,

26 Audiencia Pública en Justicia y Paz de Rodrigo Pérez Alzate del 15 de febrero de 2012.

27 Entre enero y diciembre de 2010, Coproagrosur vendió 7506300 kilos de fruto de palma por un valor de \$3676558349 M.N. (\$1300 000 dólares). Véase audiencia pública en Justicia y Paz de Rodrigo Pérez Alzate del 15 de febrero de 2012.

28 En contraposición con las cifras de expulsión, el Ruv reporta solo 8991 personas recibidas, entre 1985 y 2014. 
sin que haya evidencia que indique apropiación directa y significativa de tierras por parte de dicho grupo armado (Uribe, 2014).

Después de la desmovilización del Bloque Catatumbo, entre 2005 y 2010, Tibú experimentó un auge del mercado de tierras, que operó sobre predios abandonados forzadamente. Aunque hubo muchas transacciones que no afectaron el tamaño original de los predios, en la propiedad y el uso de la tierra hubo una concentración (Uribe, 2014). De un lado, la pequeña propiedad se fragmentó y debilitó, a la vez que la mediana y gran propiedad se fortalecieron, y de otro, se concentró el uso del suelo alrededor de tres actividades económicas: siembra de cultivos de uso ilícito (coca), ampliación de las zonas de exploración y explotación minero-energética (petróleo y carbón), e inserción y expansión del cultivo de palma de aceite. En cuanto a este último, un informe de la Procuraduría General de la Nación (PGN) señala que,

[...] se aprovechó para impulsar el negocio de la palma de aceite, en grandes extensiones de tierras abandonadas o compradas a precios irrisorios a campesinos que habían abandonado sus parcelas, por parte de empresarios financiados y condecorados por el gobierno de Álvaro Uribe, tal es el caso emblemático del ex ministro y empresario cesarence Carlos Murgas [...] los medios de subsistencia en la zona se redujeron al negocio de la coca; no hay proyectos productivos y los que hay se basan en la producción de palma africana (Verdad Abierta, s. f.).

Más de ocho mil hectáreas fueron adquiridas por vías jurídicas, pero de modo irregular, mediante estrategias que implicaron el desconocimiento de las medidas que protegían los bienes de la población desplazada, las limitaciones a la acumulación de la propiedad, el uso de medidas sofisticadas de derecho y las ventas por debajo de los precios del mercado (UAEGR, 2012; SNR, 2012).

Entre los compradores masivos de tierra estaban varias empresas palmeras (sNR, 2012). La entrada de este cultivo data del año 2000 (El Espectador, 2012). En esta fecha se impulsaron las primeras alianzas para la siembra de mil ha, en el marco de los planes de desarrollo alternativo para la región, de la mano del entonces ministro de Agricultura y con la ayuda de la cooperación internacional (USAID-MIDAS). En 2005, el ministro de Agricultura, reportó que, con recursos del Fondo de Inversiones para la Paz (FIP-Plan Colombia), del gobierno de Estados Unidos (USAID) y de la Alcaldía de Tibú, se proyectaba la siembra de 1041 hectáreas más. ${ }^{29}$ Desde entonces, el cultivo se posicionó como una de las formas más efectivas para la sustitución de cultivos ilícitos y se proyectaron cuatro mil

29 Concejo Comunal de Gobierno núm. 94. Recuperado el 26 de octubre de 2015, de http://alcandiasalesiano .blogspot.com/

P. García Reyes, J. Vargas, S. Uribe Kaffure | Estado, poder y dominio. Una lectura a propósito de sus mecanismos Perfiles Latinoamericanos, 26(51) | FLACso México | pp. 191-214 | DoI: 10.18504/pl2651-008-2018 
ha para el año 2020 (DNP, 2007). En efecto, el municipio de Tibú ha sido un receptor importante de los incentivos para el cultivo. Entre 2005 y 2014, recibió el $86.5 \%$ del crédito (ICR) otorgado en el departamento y el $9.09 \%$ en el país (MADR-Finagro). ${ }^{30}$

\section{Curvaradó y Jiguamiandó (Bajo Atrato chocoano)}

La subregión del Bajo Atrato chocoano se compone de los municipios de Acandí, Unguía, Belén de Bajirá, Carmen del Darién y Riosucio. Es un lugar muy atractivo para el tráfico de bienes de cualquier tipo, ya que es el punto más estrecho de tierra entre el océano Pacífico y el mar Caribe en Colombia, en la frontera con Panamá. En la década de 1990, el control de la zona empezó a ser disputado a las FARC por el gobierno colombiano y por los grupos de autodefensa. ${ }^{31}$ Los primeros hechos registrados de estos grupos datan de noviembre de 1995, cuando sesenta hombres de las ACCU hicieron presencia en la zona y asesinaron a seis campesinos (El Tiempo, 1996a). Esta acción generó el primer desplazamiento forzado en la región ${ }^{32}$ (Coghlan, 2004; Justicia y Paz, 2005). A partir de entonces, las acciones de estos grupos y el ejército se mezclaron. En los dos años siguientes, tuvieron lugar centenares de muertes y desapariciones, que ocasionaron el desplazamiento masivo de los pobladores dentro de la región y hacia Panamá (Defensoría del Pueblo, 2002b; Justicia y Paz, 2005). Solo en 1997, se contabilizaron 39129 personas expulsadas, de una población de $68493 .{ }^{33}$

No obstante, con el apoyo de la Iglesia católica, algunas de las familias desplazadas se organizaron bajo la figura de Comunidades de Paz, con el objetivo de retornar a sus territorios, hecho que sucedió entre 1997 y 1999, tras firmar acuerdos con el gobierno. ${ }^{34}$ Otro grupo de ellas presentó en 1998 un pliego de

30 Base de Datos Municipalizada de créditos de palma de aceite otorgados a través del ICR. Información procesada por el Observatorio de Restitución y Regulación de Derechos de Propiedad Agraria (2014). En un principio (1994-1997) fueron las ACCU, luego (1997-2006) las AUC.

32 Unas mil personas se refugiaron en el casco urbano del municipio, otras siguieron su camino hacia centros poblados y unas cuantas más cruzaron la frontera hacia Panamá (El Tiempo 1996b).

33 Red de Solidaridad Social, Sistema Único de Registro de Población Desplazada. Departamento Administrativo Nacional de Estadística, Proyecciones de Población.

34 "Acta de compromisos celebrados entre el gobierno nacional y representantes de las comunidades campesinas procedentes de Riosucio-Chocó, ubicados actualmente en el corregimiento de Pavarandó Grande, municipio de Mutatá, departamento de Antioquia." Pavarandó, Antioquia, 19 de diciembre de 1997. En 2002, se habían establecido en Riosucio 49 comunidades que sumaban cinco mil personas (Defensoría del Pueblo, 2002a). 
peticiones que incluía el retorno de 2500 familias y la reubicación de $86 .{ }^{35} \mathrm{Un}$ elemento común de las propuestas de retorno fue el de la titulación colectiva, bajo la forma de Territorios Colectivos de Comunidades Negras. ${ }^{36}$ Pese a que la titulación fue una realidad, las poblaciones de la región se encontraron con el obstáculo de la siembra de palma africana, cultivo que se vinculó de manera estrecha con los grupos paramilitares. Las razones de esta relación parecieron estar ligadas a la ampliación de las expectativas de estos grupos frente a un posible proceso de desmovilización, ${ }^{37}$ así como a los incentivos gubernamentales para la ampliación de este cultivo y su identificación como un cultivo de paz (García Reyes, 2011, 2014). En 2002, Carlos Castaño, comandante de las AUC, se dirigió a su hermano Vicente en estos términos,

[...] le doy mi concepto respecto a su proyecto de la Palma, aunque no me lo ha pedido, pero algo sé y debo decírselo: es un secreto a voces que es un propósito suyo, de alcanzarlo entrará a nivelarse con cualquier emporio de los del establecimiento, incluso promoverán su crecimiento a unas 70 o 100 mil hectáreas, como uno de los muchísimos proyectos que habrá en el posconflicto, es ese tipo de inversiones las que se negocian en los acuerdos del fin del conflicto, y se hace con el establecimiento económico colombiano o con el internacional, su caso será con este último, no lo dude, ya lo verá (Semana, 2008, 9 de agosto).

El proyecto buscó incorporar a los campesinos como aliados bajo la figura de las Alianzas Productivas. El objetivo era la siembra de veinte mil hectáreas de palma. La primera fase sería de nueve mil a cargo de Urapalma (6500 ha)

35 "Actas de acuerdos para el retorno entre las comunidades desplazadas de la cuenca El Cacarica asentadas provisionalmente en Turbo, Bocas del Atrato y Bahía Cupica y el gobierno nacional.” Turbo, Antioquia, 9 de diciembre de 1999. Una parte de los retornados se organizaron como Comunidad de Autodeterminación, Vida y Dignidad (CAVIDA). A estos se unieron tiempo después 210 personas repatriadas desde Panamá (Defensoría del Pueblo, 2002b).

36 Figura creada por el Artículo Transitorio 55 de la Constitución de 1991 y desarrollada por la Ley 70 de 1993 y sus decretos reglamentarios. En términos generales, los Territorios Colectivos son una propiedad colectiva, titulada a la población organizada en un Consejo Comunitario, el cual es, a su vez, administrador de sus recursos. Su carácter es inalienable, imprescriptible e inembargable, y su uso se restringe a actividades sostenibles como la agroforestería (Decreto 1475 de 1995). En diciembre de 1996, se expidió el primero de ellos (Resolución 0286 del 13 de diciembre de 1996 del Instituto Colombiano de la Reforma Agraria). A partir de entonces y hasta la fecha, han sido entregados 24 títulos a igual número de Consejos Comunitarios, que corresponden a cerca de 747230 ha (cálculos propios con base en resoluciones Incoder).

37 Mientras avanzaban en su proceso de consolidación territorial, las ACCU pasaron a formar parte de una organización mayor que se conformó bajo el nombre de Autodefensas Unidas de Colombia (AUC) en 1998. Con el proceso de negociación con el gobierno de Uribe (2002-2006), inició la desmovilización de sus frentes, lo cual terminó con el desarme del Bloque Elmer Cárdenas y de Vicente Castaño en 2006.

P. García Reyes, J. Vargas, S. Uribe Kaffure | Estado, poder y dominio. Una lectura a propósito de sus mecanismos Perfiles Latinoamericanos, 26(51) | FLACso México | pp. 191-214| DOI: 10.18504/pl2651-008-2018 
y Asopalma (2500 ha). Esta última, una empresa asociativa promovida por la primera que se componía de campesinos de la región y a los que se asignó a cada uno un lote de cinco ha (Defensoría del Pueblo, 2002a). Para 2002, habían contado con el apoyo de distintas instituciones del gobierno nacional, entre ellas el Ministerio de Agricultura. Además, Asopalma era beneficiaria del ICR con un crédito a doce años, con cuatro de gracia por 2476000000 M.N. (880 000 dólares actuales) (Defensoría del Pueblo, 2002b).

Bajo este esquema, los empresarios intentaron hacer socios del proyecto a los Consejos Comunitarios en cuyos territorios se había introducido el cultivo. En 2003, siete empresas palmeras y algunos integrantes del Consejo Comunitario de Curvaradó firmaron un acuerdo en el que estos últimos concedían a aquellas el uso de más de cuarenta mil ha (Justicia y Paz, 2005). En el mismo año, el representante legal de Urapalma y el correspondiente del Consejo Comunitario firmaron un acuerdo en el que este otorgaba autorización para la siembra de 1660 ha. ${ }^{38}$ En otro acuerdo, la misma empresa apareció como parte del Proyecto Palmicultor Afrocolombiano en el que figuraron siete Consejos Comunitarios del Bajo Atrato. ${ }^{39}$

Pero el modelo era inviable por las características propias de los territorios colectivos (García, 2011, 2014). ${ }^{40}$ Después de algunas gestiones de las autoridades regionales y del Ejecutivo nacional y de dos pronunciamientos de la Corte Interamericana de Derechos Humanos (Corte IDH) (Corte Interamericana de Derechos Humanos, 2003), la justicia colombiana ordenó la restitución inmediata de las tierras (Tribunal Administrativo del Chocó 2006). En 2010, la Fiscalía General de Colombia dictó orden de captura contra 23 empresarios por los delitos de desplazamiento forzado, concierto para delinquir e invasión en áreas de especial importancia ecológica. En una de las sentencias falladas en contra de dos de los empresarios involucrados en el cultivo, la justicia colom-

38 "Foro de Consejos Comunitarios de Comunidades Negras y de proyectos productivos de palma de aceite", Acta 001, 2003, mimeo.

39 "Foro de Consejos Comunitarios de Comunidades Negras y de proyectos productivos de palma de aceite", Acta 003, 2003, mimeo.

40 En 2005, un informe oficial concluyó que el 93\% de las áreas sembradas se encontraban en los territorios colectivos adjudicados a las comunidades negras de los Consejos Comunitarios de Jiguamiandó y Curvaradó y recomendó la suspensión inmediata de los negocios y la restitución de las tierras a los Consejos Comunitarios (Incoder, 2005). Un informe posterior del Instituto de Estudios Ambientales del Pacífico aclaró las cifras sobre el área sembrada, estableció la situación para 2007 y realizó un nuevo inventario de empresas. De este se concluye que para ese momento había instaladas en la zona quince empresas, de las cuales once tenían alguna actividad en los territorios colectivos. El 97\% de los cultivos y de las áreas dedicadas a la ganadería o al cultivo de palma se encontraban en los territorios colectivos. En total, un poco más de una quinta parte de los territorios, equivalente a 16977.54 hectáreas, había sido usurpada por las empresas (IIAP, 2008). 
biana estableció que ellos habían aprovechado el desalojo perpetrado por los paramilitares y participado en calidad de coautores en el desplazamiento (Rama Judicial del Poder Público, 2013).

A diferencia de los dos casos anteriores, en este, el carácter específico de la propiedad involucrada permitió la protección de las tierras del despojo legal. No obstante, las tierras fueron apropiadas de hecho y su uso fue transformado. Es posible derivar de ello mecanismos mediante los cuales el Estado ejerció su dominio en dos de las dimensiones de estatalidad al principio mencionadas: monopolio del uso de la fuerza y presencia territorial.

\section{De corsarios, amigos y Gulliveres}

Los eventos descritos muestran cómo los grupos de autodefensa, los empresarios y las poblaciones rurales se articularon en espacios institucionales delimitados por las políticas estatales de fomento al cultivo de palma africana. Lo específico es que describen formas de actuación que pueden calificarse de dominio indirecto. Es decir, se trata de formas mediante las cuales el Estado se articuló con poderes locales, legales e ilegales, para ejercer su dominio sobre dichos territorios. Es posible proponer tres mecanismos que sirvieron para ejercer tal dominio, los cuales aquí se han entendido a partir de Elster (1998): explicaciones causales de procesos sociales en los que actores interactúan enmarcados en determinados contextos y reglas de juego, con consecuencias o desenlaces indeterminados.

\section{Mecanismo corsario: privatización de la seguridad}

En su interesante análisis sobre los "empresarios militares" y la formación del Estado, Gallant (1999) señala que los bandidos y los piratas se relacionaron de manera íntima con los procesos de formación y consolidación del poder del Estado, en particular en áreas periféricas o semiperiféricas. En sus palabras, "los bandidos hicieron a los estados y los estados hicieron a los bandidos" (Gallant, 1999: 25. Traducción propia). El mecanismo corsario se inscribe dentro uno de los dos tipos predominantes de situaciones identificadas por Gallant para la implicación de "hombres de violencia" (legales e ilegales) en la conformación del Estado: jefes poderosos o nobles utilizan a los empresarios militares en sus luchas por el poder dentro de un Estado débil (Gallant, 1999: pp. 40-41). Los delincuentes de mar y tierra sirvieron a estos propósitos y el Estado, incapaz de emprender expediciones a territorios lejanos, se apoyaba en particulares para 
el ejercicio de su dominio. Fue así como las patentes de corso facilitaron la expansión del dominio europeo en ultramar.

Respecto al tema de este artículo, como se ha visto, el Estado colombiano favoreció reglas de juego y prácticas que permitieron y apoyaron el ejercicio de la seguridad en manos del patrón o del rico rural, en dos aspectos. Primero, la articulación de élites rurales a grupos privados de seguridad mediante las Convivir. ${ }^{41}$ Esta figura permitía a los miembros de una comunidad organizarse en forma de cooperativa o empresa comunitaria con el objeto de proveer vigilancia y seguridad privada a sus miembros en su área comunitaria. Por medio de las Convivir, los ricos rurales enfrentaron los ataques de la insurgencia y de paso respondieron con coerción y violencia ante las reclamaciones de los campesinos por el acceso a tierras. Algunos de estos grupos transitaron de modo natural al paramilitarismo organizado de las Auc. En específico, Julián Bolívar, comandante del Bloque Central Bolívar con acciones en San Pablo y Simití (Coproagrosur) perteneció a la Convivir Deyanac. Asimismo, Carlos Correa, uno de los primeros comandantes con dominio en el Bajo Atrato, se vinculó a la Convivir Costa Azul.

Segundo, la articulación de las fuerzas militares a los grupos paramilitares. Como ya se dijo arriba, ambas fuerzas actuaron articuladamente, por acción u omisión, en un modelo contrainsurgente que resultó muy problemático por las dificultades de coordinación que derivan del delegar la provisión de seguridad en actores privados poderosos. El disciplinamiento de estos actores resultó siempre, al menos, difícil, hecho que se evidencia en los excesos cometidos y en las técnicas de violencia utilizadas. Estas "patentes de corso" originaron el desplazamiento forzado de la población, el abandono de tierras y la profundización de la inestabilidad de los derechos de propiedad rural. Los paramilitares tuvieron medios, incentivos y mecanismos para apropiarse de las tierras mediante robos, compras forzadas y despojo, como en el Bajo Atrato o el sur de Bolívar, e implementar allí sus proyectos agroindustriales de palma aceitera; o facilitaron a través de la coerción un abandono como sucedió en Tibú que luego fue aprovechado por compradores que vía mercado adquirieron la tierra para sembrarla con el provechoso cultivo de la palma.

La advertencia de los mismos empresarios organizados en Fedepalma respecto de la promoción desmesurada del cultivo en el marco de las políticas de desmovilización y sustitución de cultivos de uso ilícito, ilustra un hecho cumplido: "el entusiasmo con el cultivo no puede impedir que le cerremos la entrada a capitales indeseables. Hay que distinguir entre planes de reinsertados o planes

41 Las Convivir fueron cooperativas armadas para la vigilancia y seguridad privadas, creadas por el artículo 42 del Decreto 356 del 11 de febrero de 1994: "Era legal armarlas, incluso con fusiles y otras armas largas, entrenarlas y dotarlas de radios de comunicación y medios de transporte” (Verdad Abierta, s. f.). 
oficiales de cultivos alternativos, e inversiones que sirvan de burladero a dinero mal habidos." (De Hart, 2004: p. 84).

\section{Mecanismo la llamada a un amigo: coaliciones para el cultivo de la paz}

Este mecanismo se refiere a las alianzas o coaliciones que consiguieron consolidar los actores legales e ilegales para promover sus cultivos de palma aceitera en territorios marcados por la coerción y con graves problemas de asignación de derechos de propiedad. En los tres casos descritos, el cultivo de la palma aceitera se ofreció como proyecto alternativo que permitiría que los desmovilizados de las AUC se reintegraran económicamente o que serviría para sustituir los cultivos de uso ilícito. Se propuso como un cultivo de paz y se dispuso de las estrategias para que fuera apoyado en un modelo de promoción del desarrollo por delegación. Los impulsores del cultivo de palma accedieron a créditos del Estado y de cooperación internacional para desarrollar sus cultivos en territorios con derechos de propiedad inestables e inseguros.

La mejor ilustración de este mecanismo es el Bajo Atrato. Allí las AUC y 23 empresas palmicultoras tejieron una compleja alianza para implementar el cultivo de palma aceitera. Primero vino la confrontación guerrillera y paramilitar, luego se impuso el dominio de este último grupo, con el correlato del desplazamiento de la población. Luego los empresarios, en alianza con los paramilitares, adecuaron la tierra e iniciaron los cultivos. Estos complejos lazos entre paramilitares, empresarios y agentes del Estado para privatizar la seguridad y para implementar y promover el desarrollo y la paz, dan cuenta de un ejercicio de dominio propio de regiones apartadas con débil presencia estatal.

\section{El mecanismo Gulliver: grandes en tierra de pequeños}

El mecanismo Gulliver hace referencia al ejercicio del dominio vía actores poderosos o grandes. Pese a que las alianzas productivas parecerían ser un juego de gana-gana, la realidad es que la única forma que tiene un pequeño campesino de acceder a los incentivos otorgados por la política de fomento para la palma es asociándose con un actor local poderoso y rico. En relación con el Coproagrosur, un grupo de campesinos se organizó y buscó créditos ante el Banco Agrario, pero les fueron negados. Posteriormente, algunos de ellos aceptaron la propuesta de los paramilitares de aliarse en la cooperativa fachada sin aportar un solo peso y trabajando como obreros en el cultivo de la palma (Verdad Abierta, 2014, 6 de junio). Solo así pudieron ser parte del negocio. Este privilegio de 
los grandes pese a la aparente orientación pro pequeños de la política (el ICR es mayor en la medida en que el proyecto tenga pequeños asociados) se debe a un hecho: el acceso al crédito,

Son los grandes productores los que han absorbido la mayor parte de los recursos del mercado formal de crédito en el sector [...] y más aún, como el Incentivo de Capitalización Rural — ICR — está atado al crédito, también este instrumento, aunque podría mostrar algunos indicadores favorables en términos de modernización del campo, genera resultados no deseados en materia de equidad. (Ramírez, 2003: p. 107).

Una evaluación de la Contraloría General de la Nación mostró que, para el periodo 2007-2009, el ICR se dirigió a la plantación y mantenimiento de cultivos de tardío rendimiento como la palma, en menoscabo de actividades orientadas a la productividad como la construcción de infraestructura y dotación de equipos. Así mismo, allí se señala que para el mismo periodo la producción de palma de aceite fue el renglón más beneficiado con cerca del $18 \%$ de los recursos. No obstante, su participación en el número de proyectos fue apenas del $0.6 \%$. Esto indica una concentración de los recursos en quienes tienen el músculo para ese tipo de cultivo, para acceder a los préstamos y para lograr los beneficios de la política de fomento (Rodríguez \& Castro, 2010).

Las asimetrías originadas por las políticas son visibles también en Tibú. Allí los campesinos quedaron en el lugar de empleados, anclados por años a contratos de exclusividad con las grandes empresas de las alianzas y con los dueños de la extractora y comercializadora del producto. Llama la atención que la empresa "ancla" en Tibú sea Promotora Oleoflores, la cual pertenece al grupo Hacienda las Flores de propiedad del ex ministro de Agricultura Carlos Murgas, conocido como el Zar de Palma.

El paramilitar Vicente Castańo, uno de los comandantes máximos de las AUC, pareció comprender el mecanismo. En una entrevista se refería a su proyecto de cultivo de palma en el Bajo Atrato:

[...] yo mismo conseguí los empresarios para invertir en esos proyectos que son duraderos y productivos. La idea es llevar a los ricos a invertir en ese tipo de proyectos en diferentes zonas del país. Al llevar a los ricos a esas zonas llegan las instituciones del Estado. Desafortunadamente las instituciones del Estado solo le caminan a esas cosas cuando están los ricos. Hay que llevar ricos a todas las regiones del país y esa es una de las misiones que tienen todos los comandantes (Semana, 2005, 5 de junio).

De esta lectura es posible observar distintas proposiciones básicas. Primero, las políticas de cultivo de palma pueden entenderse como políticas de domi- 
nio indirecto orientadas a asegurar el territorio, promover la paz y propiciar el desarrollo rural (mecanismo La llamada a un amigo). Segundo, en los casos analizados, esta modalidad de intervención delegó en privados violentos la pacificación de los territorios, lo que dificultó su coordinación, debilitó al Estado y permitió la consolidación de poderes locales violentos y oportunistas (mecanismo Corsario). Tercero, al establecerse sobre una débil regulación y aplicación de los derechos de propiedad sobre la tierra, tales políticas terminaron por tener un efecto concentrador/despojador que privilegió a los grandes en detrimento de los pobladores rurales (mecanismo Gulliver).

\section{Moraleja institucional}

La institucionalidad agraria colombiana se debilitó desde los procesos aperturistas iniciados en la década de 1980, pero se adelgazó en extremo en la última década, cuando el país desmontó una parte importante de la burocracia rural (Gutiérrez, 2010). Ante su incapacidad para incluir de manera masiva a los sectores rurales mediante reformas redistributivas amplias como la agraria o de políticas sociales para el campo, la alternativa fue la de la promoción del desarrollo y la paz por medio de terceros. Resulta difícil calificar este tipo de dominio como negativo en absoluto. Sin embargo, en situaciones como la colombiana de este artículo, caracterizada por una fuerte desigualdad rural y por procesos violentos persistentes, tal intermediación ha dejado pocos beneficiarios. En particular identificamos tres efectos. Primero, las políticas evidencian un sesgo anticampesino en tanto incentivan modelos asociativos en los que los que estos son la parte más débil. Segundo, la fórmula compuesta por procesos violentos y políticas de fomento se traduce en una descampesinización del mismo campo, en la cual los pobladores rurales pasan a ser trabajadores asalariados dentro de la cadena de producción, comercialización y consumo del cultivo. Tercero, esta forma específica de dominio aleja la posibilidad de construir un poder infraestructural en los términos de Mann (1984), toda vez que la intermediación con actores ilegales y/o violentos dificulta su regulación y corroe la legitimidad del Estado.

Así, en situaciones como las expuestas, en las que confluyen violencia, presencia de actores oportunistas o violentos y fragilidad regulatoria, el dominio indirecto produjo desenlaces indeseables. Además, la promoción de formas asociativas en entornos desiguales y violentos, conllevan el efecto de privilegiar a los ricos y a los grandes en detrimento del pequeño, si el Estado no actúa como redistribuidor real. La paradoja que enfrentan Colombia y otros países de Latinoamérica, y que describe un derrotero de desarrollo propio, es la de la construcción de una institucionalidad fuerte sobre un Estado débil. 


\section{Referencias}

Alto Comisionado de las Naciones Unidas para los Refugiados (aCnur) (2006). Proceso de Paz con las Autodefensas. Informe Ejecutivo. Bogotá: ACNUR. Recuperado el 20 de agosto de 2014, de http://bit.ly/2xhIvVl

Agencia Presidencial para la Acción Social y la Cooperación Internacional-Acción social. Proyecto de Tierras y Patrimonio de la Población Desplazada (PPTP) (2010). Estudio de tenencia municipio de Tibú, Norte de Santander. Bogotá: Equipo de Comunicaciones.

Austin, J. (Ed.). (2005). Alianzas sociales en América Latina. Enseñanzas extraídas de colaboraciones entre el sector privado y organizaciones de la sociedad civil. Bogotá: BID.

Bobbio, N. \& Bobero, M. (1984). Sociedady Estado en la filosofía moderna. El modelo iusnaturalista y el modelo hegeliano-marxiano. México: Fondo de Cultura Económica.

Castro, G. (1984). El gobierno y su política agrícola frente a la palma africana. Palmas, 5(3), $13-16$.

Coghlan, N. (2004). The Saddest Country: On Assignment in Colombia. Montreal: Mc-GuillQueen's University Press.

DANE (2012). Colombia. Necesidades básicas insatisfechas-NBI, por total, cabecera y resto, según municipio y nacional a junio de 2012. Resultados del Censo General de 2005. Recuperado el 20 de agosto de 2014, de https://goo.gl/AABkY0

De Hart, C. (2004). Hechos, suposiciones y consideraciones sobre la palma de aceite y su competitividad. Palmas, 25(2), 77-86.

Defensoría del Pueblo (2002a). Aprovechamiento forestal y derechos humanos en la cuenca del río Cacarica en el departamento del Chocó. Bogotá: Defensoría del Pueblo.

Defensoría del Pueblo (2002b). Resolución Defensorial no. 25 sobre violaciones masivas de derechos humanos y desplazamiento forzado en la región del Bajo Atrato Chocoano. Bogotá: Defensoría del Pueblo.

DNP (2007). Agenda interna para la productividad y la competitividad. Documento regional Norte de Santander. Recuperado el 10 de septiembre de 2014, de http://goo.gl/6pAewb

Edelman, M. \& León, A. (2013). Cycles of Land Grabbing in Central America: An Argument for History and a Case Study in the Bajo Aguán, Honduras. Third World Qarterly, 34(9): $1697-1722$. 
Echeverry, J. C. (2000). Medidas de apoyo a la reactivación sectorial. Palmas, 21(Especial, T2), 24-31.

El Espectador (2012, 28 de diciembre). Aceite de palma, de Tibú a Holanda. Recuperado el 10 de septiembre de 2014, de http://goo.gl/960Hk9.

El Tiempo (2010, 19 de mayo). Empresarios de la palma, a la cárcel por desplazamientos en Urabá. Recuperado el 20 de mayo de 2010, de http://goo.gl/OTsgVz

El Tiempo (1997, 28 de abril). Dejaron el alma al otro lado de la frontera, Recuperado el 27 de septiembre de 2010, de http://goo.gl/igPho8

El Tiempo (1996a, 24 de marzo). La guerra por el Urabá llega al norte del Chocó. Recuperado el 27 de septiembre de 2010, de http://goo.gl/f9aMsZ

El Tiempo (1996b, 12 de junio). Contraguerrilla vigilará El Darién. Recuperado el 27 de septiembre de 2010, de http://goo.gl/jr48po

Elster, Jon (2007). Explaining Social Behavior: More Nuts and Bolts for the Social Sciences. Cambridge: Cambridge University Press.

Elster, Jon (1998). “A Plea for Mechanisms”, en Hedstrøm, P. \& Swedberg, R. (Eds.). Social Mechanisms: An Analytical Approach to Social Theory (pp. 45-71). Cambridge: Cambridge University Press.

Fedepalma (2004). Vienen tiempos distintos y nuevas realidades para el sector palmero. Palmas, 25(1), 5-10.

Fedepalma. (1995). Economías de escala y competitividad. Palmas, 16(3), 3-4.

Fernández, R. \& García, M. J. (2012). Revisando el Estado: perspectivas y lineamientos para el desarrollo latinoamericano. Perfiles Latinoamericanos, 20(40), 35-61.

Fiscalía General sobre Patrón de Macrocriminalidad de Homicidio del Bloque Central Bolívar. Informe de Policía Judicial de fecha de 29 de julio de 2013. Fiscal 22 Delegada ante Tribunal. Unidad Nacional de Fiscalías para la Justicia y la Paz. Folios 1-39.

Fiscalía General de la Nación sobre Patrón de Macrocriminalidad de Desplazamiento Forzado del Bloque Central Bolívar. Informe de Policía Judicial 80606 (s. f.). Fiscal 22. Delegada ante Tribunal. Unidad Nacional de Fiscalías para la Justicia y la Paz. Folios 1-29. 
Gallant, T. (1999). Brigandage, Piracy, Capitalism, and State-Formation: Transnational Crime from a Historical Word-System Perspective. En Heyman, J. (Ed.). State and Illegal Practices (pp. 15-61). Oxford: Berg Publishers.

Garay, L., Salcedo, E., De León, I. \& Guerrero, B. (2008). La captura y reconfiguración cooptada del Estado en Colombia. Bogotá: Método-Fundación Avina-Transparencia por Colombia.

Garay, L., De León, I. \& Salcedo, E. (2010). La captura y reconfiguración cooptada del Estado en Guatemala, México y Colombia. Análisis conceptual de las memorias de la Primera Discusión Internacional sobre Captura y Reconfiguración Cooptada del Estado. Método. Working Paper núm. 64. Recuperado el 8 de agosto de 2015, de http://bit.ly/2xgtJ18

García Reyes, P. (2014). Tierra, palma africana y conflicto armado en el Bajo Atrato chocoano, Colombia. Una lectura desde el cambio en los órdenes de extracción. Estudios Sociojurídicos, 16(1), 209-244.

García Reyes, P. (2011). La paz perdida: territorios colectivos, palma africana y conflicto armado en el Pacífico colombiano. Tesis para optar al título de Doctor de Investigación en Ciencias Sociales con Mención en Ciencia Política. México: Flacso México.

González, F. (2003) ¿Colapso parcial o presencia diferenciada del Estado en Colombia?: Una mirada desde la historia. Colombia Internacional, (58), 125-159.

Guerra, A. (1987). La experiencia colombiana en el desarrollo de la palma aceitera. Palmas, 8(4), $7-12$.

Gutiérrez, F. (2014). Propiedad, seguridad y despojo: el caso paramilitar. Estudios Socio-Jurídicos, $16(1), 43-74$.

Gutiérrez, F. (2010). ¿Estados fallidos o conceptos fallidos? La clasificación de las fallas estatales y sus problemas. Revista de Estudios Sociales, (37), 87-104.

Gutiérrez, F. \& Zuluaga, P. (2011). Hacia un país minero: retos para el sistema político y el Estado. Nueva Sociedad, (231), 96-114.

IIAP (2008). Evaluación interdimensional de los daños ambientales ocasionados por el cultivo de palma aceitera y la ganadería extensiva en los municipios de Carmen del Darién, Riosucio (Chocó) y Mutatá (Antioquia). Quibdó: Instituto de Estudios Ambientales del Pacífico.

Incoder (2005). Los cultivos de palma de aceite en los territorios colectivos de las comunidades negras de los rios Curvaradó y Jiguamiandó, en el Departamento del Chocó. Bogotá: Incoder. 
Justicia y Paz (2005). La tramoya. Derechos humanos y palma aceitera en Jiguamiandó y Curvaradó. Bogotá: Cinep.

Mann, M. (2004). La crisis del Estado-nación en América Latina. Desarrollo Económico, 174(44), 179-198.

Mann, M. (1984). The Autonomous Power of the State: its Origins, Mechanisms and Results. European Journal of Sociology, 25(2), 185-213.

Mingorance, F. (2006). El flujo de aceite de palma Colombia-Bélgica/Europa. Bogotá: Human Rights Everywhere.

Mosquera M. (2000). Las alianzas productivas y sus obstáculos. Economía Colombiana y Coyuntura Politica, (279), 121-126.

Murgas, C. (1999). La agroindustria de la palma de aceite y sus retos para el futuro de Colombia. Palmas, 20(2), 88-92.

Ospina, M. (1998). La palma africana en Colombia. Apuntes y memorias, v. 2. Bogotá: Fedepalma.

Palm Oil Research. (s. f.). Statisitics. Recuperado el 26 octubre de 2015, de http://goo.gl/ DwkQnL

Rodríguez, J. \& Castro, R. (2010). Apoyos económicos en el sector agropecuario colombiano. Bogotá: Contraloría General de la República.

Rodríguez Castillo, L. (2006). Reflexiones socioantropológicas sobre el Estado. Perfiles Latinoamericanos, 14(28), 185-211.

Rama Judicial del Poder Público (2012). Sentencia Proceso Rdo. 2012-2015. Recuperado el 10 de abril de 2013, de http://bit.ly/2xhcyfN

Ramírez, M. (2003). Instrumentos e incentivos de política rural: ‘apoyo u obstáculo a una política de tierras? Economía y Desarrollo, 2(2), 97-117.

Salinas, Y. \& Zarama, J. M. (2012). Tierras y territorios en las versiones de los paramilitares. Bogotá: Centro de Memoria Histórica-orm.

Semana (2009, 6 de mayo). Habla Vicente Castaño. Recuperado el 10 de abril de 2013, de http://bit.ly/2xhghu7

Semana (2009, 5 de julio). El ejército abrió el Catatumbo a los paras. Recuperado el 10 de abril de 2013, de http://goo.gl/pCDWl1 
Semana (2008, 9 de agosto). De mi hermano agradezco lo más grande: estar vivo. Recuperado el 29 de septiembre de 2010, de http://goo.gl/X1eqb5

Sentencia del Tribunal Superior del Distrito Judicial de Bogotá contra Rodrigo Pérez Alzate. Sala de Justicia y Paz. 30 de agosto de 2013. Véanse también las versiones de Rodrigo Pérez Alzate y de Iván Roberto Duque en audiencia con la magistrada Uldi Teresa Jiménez López del 6 de abril de 2016.

Tilly, C. (1990). Coercion, Capital, and European States, ad 990-1992. Malden, MA: Blackwell.

Uribe Kaffure, S. (2014). Transformaciones de tenencia y uso de la tierra en zonas del ámbito rural colombiano afectadas por el conflicto armado. El caso de Tibú, Norte de Santander (2000-2010). Estudios Sociojurídicos, 16(1), 245-287.

Vaillette, C. (2005). CRS Report for Congress. Plan Colombia: A Progress Report. Washington: CRS.

Verdad Abierta (2014, 6 de junio). Cómo nació la falsa cooperativa. Recuperado el 24 de agosto de 2014, de http://goo.gl/RIsIZj

Verdad Abierta (2012, 14 de marzo). La fuerza pública fue clave para la expansión de las AUc. Mancuso. Recuperado el 10 de abril de 2013, de http://goo.gl/c1D4WU

Villalba, C. (2000). Financiamiento para el desarrollo del cultivo de palma en Colombia. Palmas, 21(Especial T2), 183-192.

Recibido el 27 de octubre de 2015. Aceptado el 9 de diciembre de 2016. 